\title{
BMJ Open 'I'd like to know what causes it, you know, anything I've done?' Are we meeting the information and support needs of patients with macular degeneration? A qualitative study
}

\author{
A E Burton, ${ }^{1}$ R L Shaw, ${ }^{2} \mathrm{~J}$ M Gibson ${ }^{3}$
}

To cite: Burton AE, Shaw RL, Gibson JM. 'I'd like to know what causes it, you know, anything l've done?' Are we meeting the information and support needs of patients with macular degeneration? A qualitative study. BMJ Open 2013;3:e003306. doi:10.1136/bmjopen-2013003306

- Prepublication history for this paper is available online. To view these files please visit the journal online (http://dx.doi.org/10.1136/ bmjopen-2013-003306).

Received 28 May 2013 Revised 9 September 2013 Accepted 14 October 2013

CrossMark

${ }^{1}$ Faculty of Health Sciences, Staffordshire University, Stoke-on-Trent, UK ${ }^{2}$ School of Life and Health Sciences, Aston University, Birmingham, UK ${ }^{3}$ School of Life and Health Sciences, Aston University, Birmingham, UK

Correspondence to Dr A E Burton; amy.burton@staffs.ac.uk

\section{ABSTRACT}

Objective: To examine patients' experiences of information and support provision for age-related macular degeneration (AMD) in the UK.

Study design: Exploratory qualitative study investigating patient experiences of healthcare consultations and living with AMD over 18 months.

Setting: Specialist eye clinics at a Birmingham hospital.

Participants: 13 patients diagnosed with AMD. Main outcome measures: Analysis of patients' narratives to identify key themes and issues relating to information and support needs.

Results: Information was accessed from a variety of sources. There was evidence of clear information deficits prior to diagnosis, following diagnosis and ongoing across the course of the condition. Patients were often ill informed and therefore unable to selfadvocate and recognise when support was needed, what support was available and how to access support.

Conclusions: AMD patients have a variety of information needs that are variable across the course of the condition. Further research is needed to determine whether these experiences are typical and identify ways of translating the guidelines into practice. Methods of providing information need to be investigated and improved for this patient group.

\section{INTRODUCTION}

Sight loss affects one in five people over the age of 75 and one in two people over the age of $90 .{ }^{1}$ Age-related macular degeneration (AMD) is a condition that causes loss of central vision and in high-income countries accounts for over a half of blind registrations. ${ }^{2}$ Cases with late or advanced AMD can be associated with a profound loss of central vision, and are classified into geographic atrophy (GA), so-called 'dry' AMD, and neovascular cases (NVAMD), so-called 'wet'

\section{Strengths and limitations of this study}

- A frequent criticism of qualitative research is the relatively small sample size. However, qualitative methods traditionally use smaller samples to ensure that the depth and detail of participant accounts can be fully understood.

- This sample included patients with a range of age-related macular degeneration conditions and all participants highlighted a variety of information deficits experienced. As all participants experienced elements of information deficit this lends support to our arguments regarding improved information provision for patients.

- This study highlights that current recommendations for verbal and written methods of information provision are unsuitable for older patients with vision impairment and illustrates that the development of new methods for providing information to these patients is required.

AMD. Recent meta-analysis studies of the epidemiology of AMD have shown that when the late AMD group is examined in large population studies, the prevalence of GA and NVAMD are equal. ${ }^{3}$ Although the treatment of dry AMD remains of limited or no benefit, there have been major breakthroughs in the management of wet AMD. Intravitreal ranibizumab injection, an antiangiogenic treatment, is the approved treatment for wet AMD in the $\mathrm{UK}^{4}$ and has been very successful. ${ }^{5}$ Delays in treatment for wet AMD may lead to significantly reduced visual acuity ${ }^{6}$ and as patients with dry AMD may also develop wet AMD, it is important that wet AMD is diagnosed as quickly as possible in this patient group.

The Royal College of Ophthalmologists' ${ }^{7}$ existing guidelines for the management of AMD patients in the UK include recommendations for diagnosis, treatment and 
management. Specific recommendations include the early provision of verbal and written information about the condition, available rehabilitation and contacts for other services. The guidelines state that all patients should receive: a clear diagnosis (knowing the name of their condition and where to seek further information and advice); vision prognosis (whether it might develop in the second eye and might 'dry' become 'wet'); treatment options, if they exist, and other support available (including counselling and low vision assessment); risk and improvement factors (such as the dangers of smoking or the value of dietary changes); the importance of continuing ocular exams; the date of their next appointment and how to monitor vision (what to do if they notice a change). The guidelines also recommend several activities for patients to monitor dry AMD and which may help identify wet AMD and thereby enable earlier treatment to be given. These include: regular ophthalmic examinations including optical coherence tomography, avoiding bright sunlight, use of the Amsler $\mathrm{Grid}^{8}$ (a grid with a central marker to focus on -if lines around the central marker become wavy this might indicate development of wet AMD) and advice on the use of nutritional supplements which in some patients may have a protective effect; ${ }^{9}$ changes in $\operatorname{diet}^{10}$ and smoking cessation. ${ }^{11}$ While some past research has indicated the link between dissatisfaction with services and perceptions of information provision in patients with a variety of types of visual impairment ${ }^{12}{ }^{13}$ little is known about how well the RCOphth guidelines have been incorporated into practice for patients with AMD. This paper reports an exploratory study which examined patients' experiences of eye health consultations and their perceptions of information and support provision for AMD.

\section{PARTICIPANTS AND METHOD}

Between May and July 2010, ophthalmologists from specialist eye clinics identified patients diagnosed with AMD and were judged capable of taking part in in-depth interviews. Interested patients were given large print information about the study to take away and agreed that their contact details could be shared with the research team. A few days later the participants were contacted by telephone to answer any questions they had about the research and to arrange a first visit with consenting participants. This study was granted National Health Service (NHS) ethical approval from Birmingham East, North and Solihull Research Ethics Committee and research and development approval from the relevant NHS trust.

Sociodemographic data were retrieved from patient notes. In-depth semistructured interviews were used to explore issues which were important to the participants in their own words. The interview schedule included questions focusing on experiences of diagnosis and other eye care consultations, the impact of AMD and related vision impairment on daily activities, relationships with and/or support needs from family and friends, and thoughts about the future. Perceptions and experiences can change over time and interviews were therefore carried out with each participant on up to three occasions over 18 months to explore perceptions of on-going encounters with healthcare professionals (HCPs) during this time. Each interview was conducted in the participants' homes and lasted 1-2.5 h. Interviews were conducted by the first author, a research student, who had no previous professional relationship with the participants (further information about the interview process has been published previously $\left.{ }^{14}\right)$. There was some participant attrition: three participants declined further involvement after the second interview stating health reasons; and two participants were unable to be contacted when arranging the third interview. A total of 34 interviews were conducted with 13 participants. Follow-up interviews at 9 and 18 months began with 'how have things been since the last time we met?'. Interviews were audiotaped, transcribed and analysis was conducted guided by the five stages of thematic analysis described by Braun and Clarke. ${ }^{15}$ These stages are: familiarisation with the data, generating initial codes, searching for themes, reviewing themes, and defining and naming themes. Theme development was completed using Nvivo V.10 software. The team (including a practising ophthalmologist) held regular meetings during the analysis process in which the developing themes were discussed and agreed upon. Extracts from the interviews are included in this paper to enhance the transparency of the analysis. To ensure anonymity participants chose their own pseudonyms.

\section{RESULTS}

\section{Sample characteristics}

Participants' characteristics can be found in table 1. Participant ages ranged from 75 to 89 with a mean age of 81.5 . Best eye visual acuity ranged from $6 / 6$ to $6 / 30$ while worst eye visual acuity ranged from $6 / 9.5$ to hand movements only $(6 / 6$ is the metric equivalent of $20 / 20$ vision). Seven of the participants were eligible for treatment and six were unable to be treated (two due to having dry AMD and three had wet AMD which was too advanced for treatment).

\section{Sources of information}

Information sources discussed by the participants included: books, leaflets and flyers; appointment letters; public events, meetings and speeches; verbal information in clinic; verbal information from opticians; and information given by other people (friends, neighbours and family members). Data extracts illustrating information sources can be seen in box 1 .

The most common source of information was verbal information given in clinic at hospital appointments. However the key problem with verbal communication 
Table 1 Participant characteristics

\begin{tabular}{|c|c|c|c|c|c|c|c|}
\hline \multirow[b]{2}{*}{ Pseudonym } & \multirow{2}{*}{$\begin{array}{l}\text { Number } \\
\text { of } \\
\text { interviews }\end{array}$} & \multirow[b]{2}{*}{ Age } & \multirow[b]{2}{*}{ Gender } & \multirow[b]{2}{*}{ Diagnosis } & \multirow[b]{2}{*}{ Treatable } & \multicolumn{2}{|c|}{ Visual acuity* } \\
\hline & & & & & & $\begin{array}{l}\text { Best } \\
\text { eye }\end{array}$ & $\begin{array}{l}\text { Worst } \\
\text { eye }\end{array}$ \\
\hline Rowans & 2 & 77 & Male & Dry AMD both eyes & No & $6 / 9$ & $6 / 12$ \\
\hline Cathleen & 2 & 80 & Female & Dry AMD both eyes & No & $6 / 7.5$ & $6 / 9.5$ \\
\hline Alison & 3 & 85 & Female & Wet AMD both eyes & Yes & $6 / 9$ & $6 / 12$ \\
\hline Irene & 2 & 86 & Female & Wet AMD one eye, dry AMD other eye & Yes & $6 / 7.5$ & $6 / 30$ \\
\hline Rose & 2 & 89 & Female & Wet AMD one eye, dry AMD other eye & Yes & $6 / 9$ & $6 / 12$ \\
\hline Nuxy & 3 & 78 & Male & Wet AMD one eye, dry AMD other eye & Yes & $6 / 7.5$ & $6 / 12$ \\
\hline Ruffine & 3 & 82 & Female & Wet AMD one eye, no AMD other eye & Yes & $6 / 6$ & $6 / 24$ \\
\hline Jordan & 3 & 75 & Female & Wet AMD both eyes & Yes & $6 / 36$ & $6 / 60$ \\
\hline Rick & 3 & 82 & Male & Wet AMD one eye, no AMD other eye & Yes & $6 / 9.5$ & $6 / 19$ \\
\hline Hermione & 3 & 80 & Female & Dry AMD and wet disconform scar & No & $6 / 15$ & CF \\
\hline Jessie & 3 & 87 & Female & Dry AMD and wet disconform scar & No & $6 / 24$ & $6 / 120$ \\
\hline Mary & 2 & 82 & Female & Advanced wet AMD, other eye unknown & No & $6 / 9.5$ & $\mathrm{HM}$ \\
\hline Jack & 3 & 82 & Male & $\begin{array}{l}\text { Advanced dry AMD and wet disconform } \\
\text { scar }\end{array}$ & No & $6 / 30$ & CF \\
\hline
\end{tabular}

*Snellen visual acuity. In order from good vision to poor: 6/5;6/6;6/7.5;6/9;6/12;6/18,6/24,6/36, 6/60, 6/60, 6/96.

$\mathrm{AMD}$, age-related macular degeneration; CF, count fingers; HM, hand movements; PL, perception of light.

was that many participants struggled to understand and retain the information given. Three participants directly discussed difficulties understanding verbal information, problems included: hearing impairment (Rick),

\section{Box 1 Data extracts-sources of information}

Verbal information given at hospital appointments: "This surgeon said, 'Of course, it's the wear and tear and your age'. Which he said quite a few times....and I thought, 'I didn't think anything was wrong with my eyes'...l've always had pretty good eyesight. So I suppose that it was a bit of a shock really." (Irene)

Letters: "When I read all [these letters] I thought, err [date] [date] [date] and I thought they've sent me these entire all at once, have they slipped up? Which one am I supposed to have?" (Ruffine) Opticians: "It worried me...It was when they wouldn't answer me and in the opticians when I said 'is it serious?' and not one of them would answer they were just looking at me. That frightened me, the life out of me, I thought it's something very, very bad" (Mary), "The optician was always very helpful with the information he gave and what was wrong with your eyes and with your eyesight deteriorating and yeah he was very good, very good." (Nuxy)

Other people: "[l see] a black cloud. My neighbor's husband had it and they said it was nothing to worry about at the hospital anyway, you know. But it doesn't last and l've heard a lot of people who say they've had it but it went off after years" (Mary) Books, leaflets and flyers: "I read things [about AMD], sometimes people give me bits out of the paper" (Cathleen), "I have got some leaflets, I haven't read them for ages" (Hermione)

Public events, meetings, speeches: "The social services woman [at the meeting], she said, 'is there anybody here that isn't on attendance allowance?' and nobody put their hand up so they was all on it, and I wrote for myself sort of thing, that when I heard about this, well it was a bit of a, well they knew why it was a bit, not as neat as I would liked it to be, and I got it straight away." (Jessie) difficulty with doctors' accents (Mary, Ruffine) and memory problems (Mary). It is likely that other participants also struggled to understand and retain information given in clinic; though they did not refer to it directly this was indicated by lack of understanding about the cause of AMD (see cause attributions in box 2), reasons for processes and procedures in clinic (see ongoing information needs in box 2) and future expectations about the condition (see box 4 ).

Letters were the second main source of information and many described struggling to read letters with some forced to ask others to read for them. For those being treated for AMD the number of appointment letters sent was overwhelming and confusing. In addition, the wait for information through letters could be a frustrating time for participants.

Six participants described how they obtained information from family, friends and other acquaintances. While in some cases this could be a useful source of information there was also a danger that the information received and acted upon was inaccurate. For example, these sources could suggest treatments were available which were actually for other conditions giving a sense of false hope: "Well, [name] had something done to his eye at the hospital, didn't he? Now, he can see better [...] he had an operation and he can see perfect" (Jack). Advice from non-professional sources also resulted in patients feeling symptoms which should be reported were nothing to be concerned about: "[I had] a black cloud. My neighbor's husband had it [...]it doesn't last and I've heard a lot of people who say they've had it but it went off after years and it's come back but not all of the time" (Mary). In addition, information from peers could cause unwarranted distress about experiencing total blindness: "it is really frightening, because I know somebody at one of my groups $[\ldots]$ 


\section{Box 2 Data extracts-equipment and information from support services}

\section{Prior to diagnosis}

"Prior to [Diagnosis] I didn't really know much about it at all...I think l'd vaguely heard about it, but I didn't really know." (Alison), "one morning that the lampposts were all curly and that really frightened me, but I wasn't sure what it was" (Hermione), "I didn't realize that it was so common. Until you go up there and when you see the amount of people about. You know, l'd never heard of it in actual fact. But when you see the number of people at [hospital] especially, it's always packed out." (Nuxy)

Following diagnosis

Cause attributions: "We don't really know what's caused it."(Jack), "When I was a little girl I put the scissors in the eye and of course that weakened the right eye" (Mary), "l'd like to know what causes it, you know, anything l've done?" (Cathleen)

Processes and procedures: "'ve got to go next month. So, whether they'll [treat] the one eye today and then do the other eye next month, I don't know."(Jordan), "Well, do you know what frightened me, [interviewer]? The photography, I thought it was never going to end. And it was every 8 minutes he was coming in and your back was killing you in the high chair." (Mary), "I'm going, as I say l'm going up there next month, I don't know what the procedure is going to be, but they don't tell you do they? They don't tell you." (Rick)

Equipment and support services: "I have a horror of, not a horror, but I have, I don't feel I want to be part of a group where everybody is, or you might get some people who are, sadly, feeling very down about it, bless them, or grumbling about it, and you know? I can't do this and I can't do that, and l'd rather not, and that probably isn't the way it would work l'm sure not, but until I do need more help I haven't." (Hermione), "I went to the, had the [Low vision assessment] test there, you know it's very good, very good they were, but it's so far away, you know, being, on the buses and things like that, l've actually enquired how to get there but no one seems to know how I can get there on the bus." (Jessie), "Interviewer: Is there any support you'd like to receive that you are not receiving that would help you? Rick: I don't know what would be, support there is" (Rick)

Vitamins: "I got about five different lots which I took up [to the hospital]. I plonked than down and said 'now tell me which are the best ones?'. He said, 'I Caps'. And I thought. 'I can't win'. He didn't look at the others."(Cathleen), "I was advised to take those [I-caps] and that's supposed to help it to not get any worse."(Jessie)

Registering as blind or partially sighted: "He said that you could be registered as part-sighted. Well what does that mean? What does it do? Does it open the door for different things?" (Jack)

Smoking: "I used to be a heavy, well I do, I still do smoke." (Rick)

Activities you should and shouldn't do: "I keep sort of thinking oh I will do [some painting] and I think no, I sort of put a limit on how much I use my eyes a lot, does this make sense to you?" (Alison)

Ongoing information and support needs

Reasons for medical processes and procedures: "I have to go next month, I'm supposed to have the other eye done. Well, this is what I could assume, it might be about today I don't know." (Jordan)

Registering as blind or partially sighted: "I mean someone said you could get more aids [if you registered as partially sighted] or something, or like from different places, I don’t know." (Jack)

How to monitor vision for changes (see self-advocacy theme in Box 3)

who says she's got dry macular, but she's, she can't write her name, she, she's virtually blind, so it isn't just with the wet macular that you can go blind, it's with the dry as well isn't it?" (Cathleen).

Books, leaflets and flyers were mentioned as a source of information by just under half of the participants; however, like letters these could be difficult to access. Some leaflets given by the hospital were unread and forgotten about. For example, Jessie described how her granddaughter 'ordered some booklets about help which you can get' but the act of reading was 'difficult' because the words were 'jiggling' around and she continued to put off looking at the leaflets she had been given: "one of these days I'll sit down and study the lot". The other danger of ad hoc access to information through books and newspapers was the risk of being given inaccurate information. For example, Cathleen explained that she collected newspaper cuttings, leaflets, books, 'all this lot, anything I find' and was at risk of being overwhelmed by information: "I don't know, you just don't know really what you're doing."

Five participants (Hermione, Jordan, Mary, Nuxy and Rose) mentioned receiving information about their condition from their optician. These participants reported contrasting experiences of dealing with opticians with some perceiving their appointments positively and others negatively. For Mary her diagnosis experience was made more stressful by the optician's failure to adequately inform her about what was happening (see box 1).

Jessie and Alison discussed attending group meetings and speeches about AMD as a source of information. These sources were a good way to access information they may not have had access to, and for Jessie they enabled an application for attendance allowance which may not have otherwise occurred.

\section{Equipment and information from support services}

All 13 participants discussed equipment provided and the information received from HCPs and support services and for many these highlighted information deficits. Deficits were described across three time periods: information needs prior to diagnosis; information needs following diagnosis and ongoing information needs throughout the course of the condition. Data extracts relating to equipment and information from support services are in box 2 . 


\section{Box 3 Data extracts-self-advocacy}

Desire to be monitored by healthcare professionals: "I would like an appointment. I would like a follow-up appointment. [The] Dr said that if l've got any problems, just go to accident and emergency." (Cathleen), "The trouble is, at the eye hospital they examined my eyes and everything but they don't give me a follow-up."(Jack), "They said, there is nothing we can really do he said, we'll see you in four months, and then we'll see you in six months and then you needn't come again if you don't want to but if you want to you can, and I said, and I will! Because I would rather remain under the hospital, because if there is an emergency they've got it all there for you haven't they?" (Mary), "I know it's a nuisance having to keep going but at least I know that they will be checking on me you know?" (Ruffine)

Responsibility for monitoring vision and detecting changes: "I mean, that's another thing that the doctor said to me, about the chart, the Amsler grid. It's going, just at the top, on the right hand side, it's going wavy. And she said well don't worry about that too much. Well I thought that was the actual thing that l'd got to worry about. You know, she's just said when everyday objects start getting all out of shape, then come back. And I thought I want to come back before then. I want to know the minute it starts, it turns into a wet macular. And I don't know if I shall." (Cathleen), "I mean it's fine isn't it, for someone to say to you, well you would notice a change because... but you can't be sure...I'm not sure what l'm looking for! I mean obviously if I suddenly couldn't see or some dramatic change, but would it be as dramatic as that?" (Hermione), "I am going to see somebody about some aids, you know? Magnifying glasses. But I had to ask... It must be terrible for elderly people who perhaps can't ask these things, you know? They must just be out, and that's it."(Jack)

\section{Box 4 Future expectations}

Hope: "I am hoping obviously that...I'm hoping that this one [eye] will return [to what it was]" (Alison) "Well the treatment I suppose it's peace of mind mostly. To think well at least I'm responding to that treatment, it's gone quite a lot better, and I'm very pleased that it's gone myself, which they are as well, so I suppose the thought, the thought as well, we're hoping anyway, is it don't get any worse now, and if that's it I shall be very pleased." (Irene), "Well, I'm hoping that they stop like they are, because I'm getting accustomed to it, and I'm hoping that those (I-caps) work, that they'll stabilise it".(Jessie), "I just leave it at the back of my mind and I think, don't think of it too much at the moment and hope it will be alright". (Rowans)

Fear and Uncertainty: "I feel now... a bit in limbo, just waiting till everyday objects go a peculiar shape." (Cathleen), "I worry about it a little bit because of the dependency later on, I do find just occasionally in the night I wake, and I find I'm worrying about it." (Hermione), "I worry about shopping and it just managing the basic things you know? I don't think any farther than that really." (Jack) "I suppose l've got to put up with this now for the rest of my life. I don't think it's a killing thing this is it [interviewer]?" (Mary).

Nine participants (Alison, Hermione, Irene, Jordan, Mary, Nuxy, Rick, Rowans and Ruffine) talked about issues which highlighted that they had little or no knowledge of AMD prior to their eye care consultation and as a result diagnosis came as a shock to them.

A wide variety of information deficits following diagnosis was evident in the accounts: the cause of AMD, reasons for medical processes and procedures, vitamins, registering as partially sighted, impact of smoking, foods for eye health and activities they should or should not pursue. These are all issues which the RCOphth guidelines recommend information to be provided for. Lack of knowledge about the cause of AMD (various suggested causes were discussed, ie, age, over use of the eyes, eye trauma, previous treatments for eye conditions and other medical conditions) links to the lack of knowledge about AMD prior to diagnosis. Without prior knowledge of AMD the participants lacked a frame of reference on which they could make sense of their newly diagnosed condition. In the case of AMD there is a lack of knowledge 'out there' in society meaning patients are totally dependent on the information given to them by HCPs.

A lack of knowledge about the purpose of medical processes and procedures was also highlighted. For example, letters were often unclear about the purpose of appointments. In addition during long 3-4 h appointments patients were not made aware of the purpose of scans and other procedures. Despite the value of taking vitamins and the recommendations for making patients aware of these, only four participants (Cathleen, Hermione, Jack and Jessie) discussed the use of vitamins, and all were unsure of their purpose or which were the most beneficial to take. Only two participants (Jack and Jessie) mentioned the opportunity to register as blind or partially sighted and both seemed uncertain about the purpose and value of being registered. Three participants reported smoking (Jordan, Rick and Ruffine), and none discussed the impact this may have on their eye health. Two participants (Alison and Jessie) suggested they had given up activities they enjoyed (reading and painting) in the hope that by doing this they would use their eyes less and therefore preserve their remaining vision. This myth about over use of the eyes contributing to AMD may not be helped by HCPs description of the condition as 'wear and tear' and could be addressed by altering the way in which the condition is explained to patients.

Few participants were aware of the support services available to them. Many spoke of using magnifying glasses and while some had been provided by social services or charities others had bought equipment for themselves. Despite knowledge of support groups there seemed a fear that these groups were for people overwhelmed by their condition and would not be enjoyable to attend ("I know in many ways it's a good idea because you exchange ideas and you pick up tips but equally, this sounds unkind, I know people tend to dwell sometimes on what is wrong with them and I personally don't think that's a good thing in a group" Hermione). 
There was a clear need for ongoing information across the course of the condition. It seemed that an individual's information needs differed dependent on the stage of the disease. Those with early AMD had a greater need for information about monitoring their condition and identifying changes. Patients with treatable wet AMD needed to know about the process and outcomes of treatment. Once diagnosed with advanced forms of the condition patients had a need for information about available support services and equipment. Evidence that some participants were unaware of what support was available to them is concerning as the participants described being expected to self-advocate and identify their own needs.

\section{Self-advocacy}

Data extracts for this theme can be seen in box 3 .

Almost half of the participants expressed a desire for regular monitoring by HCPs. It seemed that the traditional view of healthcare (HCPs are the experts, we tell them our symptoms and they monitor our symptoms and treat us) prevailed and therefore knowing that they were under the care of the hospital gave a sense of security. Those receiving treatment for wet AMD automatically received on going appointments and those with other conditions such as diabetes, cataracts or glaucoma were also frequently monitored by other clinics able to refer them back to an AMD clinic if additional problems were identified. For participants with early or advanced dry AMD or untreatable wet AMD there were no regular appointments and most were discharged from the hospital. These participants were often advised to attend the Emergency Department (ED) if any problems with their vision occurred; however most were uncertain of what changes they needed to identify and how serious problems needed to be before they sought assistance. Some of the participants referred to instruction to attend the ED as needing to attend 'A\&E' (a service traditionally associated with accidents). These patients may choose not to attend the ED as in their minds it represents an A\&E service which is designed for accidents rather than the type of emergency they were experiencing; a change in vision which would not be considered an 'accident'. This distinction in terminology could have important implications for a patient's decision to seek help at the point of visual deterioration.

Eight of the participants (Alison, Cathleen, Hermione, Jack, Jessie, Mary, Rowans and Ruffine) highlighted the need to self-advocate; they were expected to identify advancing vision loss and seek the appropriate support as and when it was necessary. Most did not feel they were adequately informed to identify any 'big changes' in vision that warranted a return to the hospital. This again relates to patients lacking prior knowledge about AMD and therefore not having a frame of reference on which to base their experiences. In addition, the experience of vision loss was new to these patients making their ability to describe and make sense of their symptoms extremely challenging. Cathleen's statement 'I'm not sure what I'm looking for' illustrated that she did not possess the first hand experiential knowledge to be able to identify changes in her vision as instructed by the HCPs whose clinical knowledge meant that identification of these changes represented a process for successful diagnosis. The patient's experiential knowledge was clashing with the clinician's expert knowledge because the clinicians did not use language patients could understand and relate to their own embodied experience of worsening vision.

In addition some participants worried about bothering the hospital and wasting hospital time unnecessarily. Patients are likely to be aware of the ongoing media speculation about the pressures on hospital services which are being overwhelmed and this again may impact on their decision to seek help from EDs. As aforementioned, patients are unlikely to perceive changes in vision as 'accidents' and therefore are reluctant to become an added drain on overworked departments. Another example of self-advocacy is evident in Jack's description of sourcing his own appointment for a low vision assessment.

\section{Future expectations}

The participants were all asked about their expectations of their future with AMD, data extracts relating to this theme are shown in box 4 .

The responses fell into two main categories: fear and uncertainty, and hope. Hope was more prominent in the patients with treatable wet AMD as access to treatment afforded them the prospect of improvement. In comparison, those with no possible treatment often spoke of fear and uncertainty about what the future may be like.

The way a patient with AMD approaches their future, either with hope or with fear, will have important implications for their adaptation to the condition. Cathleen, for example was, "frightened of falling, you know, not being able to see. You know not really being able to cope" and this fear had fuelled her desire and search for information. Unfortunately the majority of this information came from ad hoc sources (as discussed previously) rather than directly from HCPs and as a result fear continued to permeate Cathleen's life. Had Cathleen's need for information been addressed more formally in a healthcare context Cathleen perhaps would have more confidence to be able to identify and monitor changes in her vision and prevent the 'very limited life' that she feared. Information provision from trusted sources in a format accessible to the individual patient is vital for ensuring on-going mental well-being.

\section{DISCUSSION}

This study has given insight into the variety of information deficits which can be experienced by patients across the spectrum of AMD forms and stages. There appear to be deficiencies in current information provision and 
these findings demonstrate a need to find ways to translate the RCOphth guidelines into practice. This information needs to be continually updated to reflect major advances in the understanding of AMD, including the role of genetics, ${ }^{16}$ the AREDS 2 study and its implications for nutritional advice ${ }^{17}$ and advances in retinal imaging. In addition, the information that patients require will very much depend on their stage and type of AMD. Patients with early and intermediate AMD, who still have good vision, may benefit from advice on nutritional information and smoking cessation whereas patients with late AMD probably will not benefit from this advice.

It is clearly of concern that we have found that the information in the current guidelines is not being enacted and future work is required to determine whether these deficiencies are typical and how to overcome them. Based on these findings and our other analyses $^{1418}$ further work related to improving information for patients with AMD is in development. While clinical guidelines recommend that patients are given a wide variety of information about their condition, the experiences of these participants suggest that current information provision may be insufficient.

Recommended activities for older people, such as taking supplements and changing diet, may play an important role in reducing the risk of further visual deterioration. However only four of the participants discussed taking recommended vitamins and for most this was based on a specific recommendation made by a healthcare practitioner. Participants did not seem aware of the purpose and value of supplements and this may have serious implications for adherence to regimens. For example, in other eye conditions such as glaucoma it has been suggested that compliance is often dependent on beliefs about the efficacy of the eyedrops. ${ }^{19}$ As vitamins and nutritional supplements are not generally prescribed for AMD by the NHS (and therefore not compulsory) their efficacy may be questioned and this may help to explain why adherence to recommended supplement regimens has been reported to be low in AMD patients. ${ }^{20}$

Some conditions, such as diabetes, have symptoms which are more easily recognised as the result of disease $^{21}$; however, AMD symptoms involve changes in visual ability which may be assumed to be a result of 'normal ageing'. In these instances the individual may not attribute their symptoms to a developing health condition and instead accept them as a common complication of the ageing process; a conclusion which is sanctioned by HCPs' description of AMD as 'wear and tear'. Most of the participants in this study were unaware of AMD prior to diagnosis and most were not adequately informed about the course of their condition and expressed fear about the future an issue which has been shown to impact on patients' satisfaction with ophthalmology services. ${ }^{22}$

Work exploring Parkinson's disease, another unpredictable condition in old age, has highlighted that patients and HCPs have different sorts of knowledge about living with a long-term condition and use different strategies to manage the inherent uncertainty and the anxiety diagnosis may provoke. ${ }^{23}$ HCPs may have clinical expertise but patients have knowledge of what living with the condition is like for them. In order to improve practice HCPs need to see patients as more than 'diseased bodies' and attempt to empathise and understand how being diagnosed with a long-term condition and dealing with the healthcare service feels from a patient's perspective. ${ }^{24}$

Research within ophthalmic practice confirmed that patients want information tailored to their needs and that this is vital to ensure that patients play an active role in the management of their condition. ${ }^{24}$ The fear and uncertainty reported in this study illustrates that patients may need improved support and reassurance from HCPs who understand what it is like to live with AMD. Patients need more than medical treatment for their condition and may need counselling or emotional support to enable them to cope with the changes AMD causes to their lives, roles and self-concepts. ${ }^{14}$ This change in outcome is dependent on a change in the behaviour of HCPs whose role in patient-professional interactions has important implications for a patient's experience of the condition. ${ }^{25} 26$

This change in approach to information provision is imperative in a practice model which expects patients with AMD to identify important changes in their vision and seek appropriate and timely support. As already highlighted many patients lack the knowledge necessary to be able to self-advocate; an issue commonly overlooked when caring for patients with visual impairment. ${ }^{27}$ An additional problem is encountered through the discontinuity of services which are spread across sectors within the UK. While the NHS provides ophthalmology clinics through referral from private high street optometrists there are also a number of third sector organisations offering support (ie, Royal National Institute of Blind People; RNIB, Macular Society, etc). These third sector support services are well placed to play a key role in the provision of information and support in order to relieve the pressure on ophthalmologists. At present patients need to be proactive in seeking this support and a more structured care pathway should be developed to ensure patients access third sector support following consultation.

Another key problem is the way in which information is delivered to patients. Current guidelines suggest written and verbal information should be provided, however the stress of diagnosis may result in verbal information being forgotten, while visual impairment may reduce ability to access written material. This may leave patients confused about what is required of them and therefore unable to play an active role in managing AMD. In addition, while services may be offered to patients soon after diagnosis the progressive nature of AMD and changing environmental demands may 
require on-going adaption by the patient. Once discharged, services may become increasingly difficult to access. ${ }^{25}$ Our study has shown that patients have differing information needs before, after and in the long-term following diagnosis. Support should not end at the point of discharge. Patients with AMD need ongoing opportunities to be offered follow-up and support across the course of the condition.

\section{Recommendations for practice}

To ensure a patient-centred approach to future services for patients with AMD there is a need to develop a care pathway incorporating adequate and appropriate information provision that bolsters a patient's self-efficacy and self-advocacy. Information provision for patients needs to be improved and become less reliant on written and verbal methods which may be unsuitable for many patients. In addition HCPs need to do more to understand the perspectives of individual patients in order to help them assimilate information and make sense of the progressive condition with which they have been diagnosed. This often requires more than medical intervention and illustrates a need for ophthalmology patient pathways to include referral to counselling and social support services to help the patient come to terms with and adjust to progressive vision loss. These services need to be easily accessed by patients even after the point of discharge and patients therefore need regular follow-up appointments to assess their physical, social and psychological needs.

\section{Limitations of the study}

Qualitative methods traditionally use smaller samples to ensure that the depth and detail of participant accounts can be fully understood. In addition recruitment for this study took place in a busy clinic meaning that a purposive form of sampling would be challenging. Despite this the sample included patients with a range of AMD conditions and all participants highlighted a variety of information deficits experienced. As all participants experienced elements of information deficit this lends support to our arguments regarding improved information provision for patients. In addition, data collection for this study took place in 2010 and given that the RCOpth guidelines were published in 2009, this may not have allowed enough time for the guidelines to be translated into practice. Conclusions from these data about 'current' practice should be interpreted with caution and as nearly 3 years have passed since the data were collected, experiences of patients with AMD may now be different. Despite this the results provide a valuable starting point to further investigate the issues raised.

\section{CONCLUSION}

This study has highlighted many areas where further research is needed to address the information needs of patients with AMD and to design services to ensure they receive the best possible care, and up to date information. New ways to deliver information need to be developed to ensure this is understood and retained and patients are motivated to take steps to monitor and preserve their vision. HCPs need to be educated about the best ways to communicate with patients to ensure that care is patient focused.

\section{Statement of confidentiality}

I confirm all patient/personal identifiers have been removed or disguised so the patient/person(s) described are not identifiable and cannot be identified through the details of the story.

Contributors AEB contributed to the design of the study, participant recruitment, collection of data, analysis of data, drafting and revision of the manuscript. RS contributed to the design of the study, supervision of recruitment and data collection, refinement of analysis and drafting and revision of the manuscript. JG contributed to the design of the study, participant recruitment, refinement of analysis and drafting and revision of the manuscript.

Funding This work was supported by a studentship provided by Aston Research Centre for Healthy Ageing (ARCHA), Aston University.

Competing interests JG has received honoraria for travel to conferences and Advisory Boards from the following pharmaceutical companies: Novartis, Allergan, Alimera and Bayer. Aston University has received research grant money from Novartis.

Ethics approval Birmingham East, West and Solihull NHS Research Ethics committee.

Provenance and peer review Not commissioned; externally peer reviewed.

Data sharing statement Further data related to this research are available through access to the PhD thesis on which this work is based. Burton AE (2012). The experience of living with age-related macular degeneration: a longitudinal study into the impact of age related macular degeneration on quality of life. PhD Thesis, Aston University, Birmingham, UK.

Open Access This is an Open Access article distributed in accordance with the Creative Commons Attribution Non Commercial (CC BY-NC 3.0) license, which permits others to distribute, remix, adapt, build upon this work noncommercially, and license their derivative works on different terms, provided the original work is properly cited and the use is non-commercial. See: http:// creativecommons.org/licenses/by-nc/3.0/

\section{REFERENCES}

1. Access Economics. The economic impact of partial sight and blindness in the UK adult population. Report for the Royal National Institute of Blind People. London, 2009.

2. Bunce C, Wormald R. Causes of blind certifications in England and Wales: April 1999-March 2000. Eye 2008;22:905-11.

3. Rudnicka AR, Jarrar Z, Wormald R, et al. Age and gender variations in age-related macular degeneration prevalence in populations of European ancestry: a meta-analysis. Ophthalmology 2012;119:571-80.

4. National Institute for Health and Clinical Excellence. Ranibizumab and pegaptanib for age-related macular degeneration: appraisal consultation document. London: Department of Health, 2007.

5. Brown DM, Kaiser PK, Michels M, et al. Ranibizumab versus verteporfin for neovascular age-related macular degeneration. N Engl J Med 2006;355:1432-44.

6. Arias L, Armada F, Donate J, et al. Delay in treating age-related macular degeneration in Spain is associated with progressive vision loss. Eye 2009;23:326-33.

7. The Royal College of Ophthalmologists. Age related macular degeneration: guidelines for management. London: Royal College of Ophthalmologists, 2009. 
8. Jager RD, Mieler WF, Miller JW. Age-related macular degeneration. N Engl J Med 2008;358:2606-17.

9. Age-Related Eye Disease Study Research Group. A randomized placebo-controlled clinical trial of high-dose supplementation with vitamins $C$ and $E$ beta carotene and zinc for age-related macular degeneration and vision loss: AREDS report no 8. Arch Ophthalmol 2001;119:1439-52.

10. SanGiovanni JP, Chew EY, Clemons TE, et al. The relationship of dietary carotenoid and vitamin $\mathrm{A} E$ and $\mathrm{C}$ intake with age-related macular degeneration in a case-control study: AREDS Report No 22. Arch Ophthalmol 2007;125:1225-32.

11. Evans JR, Fletcher AE, Wormald RP. 28000 Cases of age related macular degeneration causing visual loss in people aged 75 years and above in the United Kingdom may be attributable to smoking. Br J Ophthalmol 2005;89:550-3.

12. Douglas G, Pavey S, Corcoran C, et al. Individuals recollections of their experiences in eye clinics and understanding of their eye condition: results from a survey of visually impaired people in Britain. Opthalmic Physiol Optics 2012;30:748-57.

13. Mitchell J, Bradley P, Anderson SJ, et al. Perceived quality of health care in macular disease: a survey of members of the Macular Disease Society. Br J Opthalmol 2002;86:777-81.

14. Burton $A E$, Shaw RL, Gibson JM. Experiences of patients with age-related macular degeneration receiving anti-vascular endothelial growth factor therapy: a qualitative study. Br J Vision Impair (in press).

15. Braun V, Clarke V. Using thematic analysis in psychology. Qual Res Psychol 2006;3:77-101.

16. Ratnapriya R, Chew EY. Age-related macular degeneration-clinical review and genetics update. Clin Genet 2013;84:160-6.

17. Age-Related Eye Disease Study 2 Research G, Chew EY, SanGiovanni JP, Ferris FL, et al. Lutein/zeaxanthin for the treatment of age-related cataract: AREDS2 randomized trial report no. 4. JAMA Ophthalmol 2013;131:843-50.
18. Bennion AE, Shaw RL, Gibson JM. What do we know about the experience of living with age related macular degeneration? A systematic review and meta-synthesis. Soc Sci Med 2012;75:976-85.

19. Lacey J, Cate H, Broadway DC. Barriers to adherence with glaucoma medications: a qualitative research study. Eye 2009;23:924-32.

20. $\mathrm{Ng} \mathrm{WT}$, Goggin M. Awareness of and compliance with recommended dietary supplement among age-related macular degeneration patients. Clin Exp Ophthalmol 2006;34:9-14.

21. Peel E, Parry O, Douglas $\mathrm{M}$, et al. Blood glucose self-monitoring in non-insulin-treated type 2 diabetes: a qualitative study of patients' perspectives. Br J Gen Pract 2004;54:183-8.

22. Garcia-Gutierrez S, Quintana JM, Aguire U, et al. Impact of clinical and patient-reported outcomes on patient satisfaction with cataract extraction. Health Expect 2012 Jul 11; [Epub ahead of print]. doi: 101111/j1369-7625201200801x

23. Pinder R. The management of chronic illness: patient and doctor perspectives on Parkinson's disease. London: Palgrave Macmillan, 1990.

24. Flynn F, Grunfeld EA, Turvey A, et al. Four different types of client attitudes towards purchasing spectacles in optometric practice. Health Expect 2005;8:18-25.

25. French SD, Green SE, O'Connor DA, et al. Developing theory-informed behaviour change interventions to implement evidence into practice: a systematic approach using the Theoretical Domains Framework. Implement Sci 2012;7:38.

26. The Improved Clinical Effectiveness Through Behavioural Research Group (ICEBeRG). Designing theoretically informed implementation interventions. Implement Sci 2006;1:4

27. Sharts-Hopoko NC. Lifestyle strategies for the prevention of vision loss. Holist Nurs Pract 2010;24:284-91. 